\title{
OCULAR MANIFESTATIONS IN IDIOPATHIC HYPERLIPAEMIA AND XANTHOMATOSIS*
}

\author{
BY \\ P. K. THOMAS $\uparrow$ AND E. B. SMITH \\ Department of Neurology and Courtauld Institute of Biochemistry, \\ Middlesex Hospital
}

THE accumulation of neutral far in the blood to such an extent as to produce turbidity of the serum is termed hyperlipaemia. This may occur physiologically after a fatty meal, secondarily to diabetes mellitus, the nephrotic syndrome and glycogen storage disease, or idiopathically.

The literature on idiopathic hyperlipaemia has recently been reviewed by Lever, Smith, and Hurley (1954), who collected 41 cases from the literature, to which they added seven of their own. The condition is not infrequently familial and may begin in childhood; in two-thirds of the cases reviewed by Lever and others (1954), the disease was discovered before the age of 30 . It may be accompanied by cutaneous xanthomata; the histological features of these eruptive xanthomata have been considered by Thannhauser and Magendantz (1938). Xanthomata of the tendons are also encountered. Episodes of abdominal pain, probably from pancreatitis, are common, and coronary artery disease may occur. The spleen and liver are frequently enlarged and glycosuria may be found.

With respect to the blood lipids, cases of xanthomatosis exhibit two extreme types:

(1) Hypercholesteraemic xanthomatosis, where there is a clear serum, a great increase in cholesterol with little increase in neutral fat, and an electrophoretic lipoprotein pattern that differs from the normal only in the occurrence of a very high $\beta$-lipoprotein fraction;

(2) Hyperlipaemic xanthomatosis, where the serum is grossly lipaemic and there is an electrophoretic pattern in which the $\beta$-lipoprotein is submerged in a mass of other lipid; the hypercholesteraemia is moderate, and Thannhauser (1950) suggests that it is secondary to the hyperlipaemia.

The two conditions do not, however, appear necessarily to be of unrelated aetiology, since Smith (1956), in a study of thirteen cases of xanthomatosis, five of which were examples of idiopathic hyperlipaemia, found two that appeared to change in type during a follow-up period of about a year. One changed strikingly from an apparently pure hypercholesteraemia to a moderately severe hyperlipaemia and the other lost the moderate degree of hyperlipaemia that was present when he was first seen.

* Received for publication July, 29, 1957.

$\uparrow$ Formerly House Physician, West End Hospital for Neurology and Neurosurgery. 501 
The present case, which falls into the latter category, is unusual because of its presentation with visual failure and also in the occurrence of retinal xanthomata; it is reported for this reason, together with some observations on the nature of the biochemical disturbance.

\section{Case Report}

A 58-year-old woman was admitted to the West End Hospital for Neurology and Neurosurgery in July, 1954; 5 months before her admission she had discovered, on accidentally covering the left eye, that the vision in the right eye was blurred. Subsequently, the vision had improved, but central blurring had remained.

Her previous medical history included a cholecystectomy in 1953, because of gall stones. Symptoms referable to this condition dated back for 10 to 15 years. Since the age of 30, recurrent cutaneous papules, which were described as containing yellowish material, had been present, mainly over the elbows, knees, and outer sides of the feet. It is of interest that the patient had observed that these had subsided when she had been placed on a low fat diet because of her gall bladder disease.

The patient had two daughters and a son. She had an elder sister and a younger halfsister; another half-sister had died during childhood from tuberculosis. The patient knew of no relatives with any similar disorder and there was no known consanguinuity. Of those just mentioned, it was only possible to examine the blood of the patient's two daughters; neither showed a macroscopic lipaemia.

Examination.-The visual acuity was $6 / 60$ in the right eye and 6/12 in the left (with glasses). The peripheral fields were full in both eyes, but in the right there was a large central scotoma (Fig. 1). The right fundus showed oedema of the macular region,

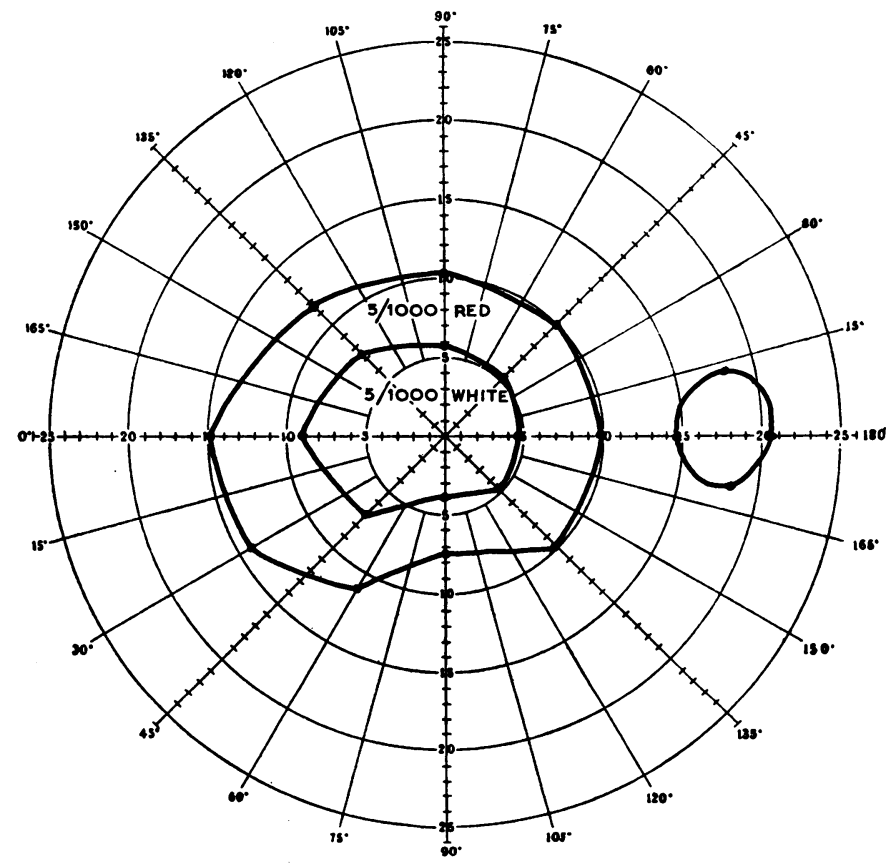

FIG. 1.-Bjerrum screen chart indicating scotoma. 
together with old haemorrhages in this area. Of particular interest was the presence of fairly numerous small, yellowish-white, clearly defined deposits, distributed especially along the lines of the vessels; these were considered to represent minute xanthomata. The left fundus also showed these deposits but was otherwise normal (Fig. 2). Lipaemia retinalis was not observed. Vertical nystagmus and horizontal nystagmus on lateral deviation of the eyes to both sides was present, but there were no other abnormal neurological signs.

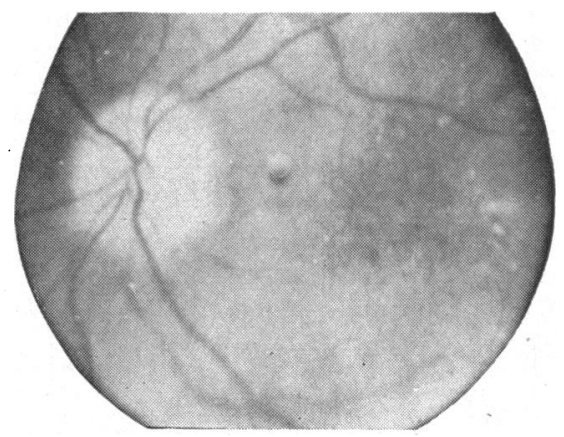

FIG. 2.-Retinal photograph of case described in text.

On the lateral aspects of both feet were clusters of reddish papules with a central yellow area, the largest being approximately $1 \mathrm{~cm}$. in diameter. At other times, linear streaks of small xanthomata were noted on the shins, presumably in the-line of scratches with the nails.

The spleen was moderately enlarged and the liver edge palpable $6-7 \mathrm{~cm}$. below the costal margin. Otherwise examination yielded nothing of significance except for a blood pressure of $180 / 100$.

Macroscopic lipaemia was discovered on taking a sample of venous blood.

Progress.-After investigation, the patient was discharged on a low fat diet and was re-admitted for further assessment after periods of 3 months and 1 year. On her last admission, the findings were essentially unaltered, save for the fact that the macular region on the right now showed pigmented degenerative change. The visual acuity was unaltered and there was no significant change in the size of the scotoma. The size of the liver and spleen was relatively unchanged, but the patient admitted that she had not kept rigidly to the diet.

\section{Haematological Findings}

\section{Laboratory Investigations}

No abnormality of the peripheral blood was detected at any time. Biopsy of the sternal marrow showed foamy vacuolation of the reticulum cells. These were not obviously increased in number, but some were so swollen with droplets that they reached sizes of up to $65 \mu$ in diameter. Certain cells resembling monocytes also showed a similar vacuolation of their cytoplasm in lesser degree. The marrow was otherwise normal.

\section{Biochemical Findings}

The serum lipoproteins were examined at two periods; four separate serum samples were examined during July, 1954, and three samples during October and November, 1955. There was possibly some very slight improvement at the latter 
period, but in all samples examined the lipids were grossly abnormal, the fresh serum being very milky and the lipoprotein emulsion unstable, separating into a layer of "cream" and a more or less clear infranatant on standing.

\section{Analytical Data}

Total cholesterol $367 \mathrm{mg}$. per cent. (Normal range $-250 \pm 50 \mathrm{mg}$. per cent.)

Lipid phosphorus $16 \cdot 5 \mathrm{mg}$. per cent.

Phospholipid $412 \mathrm{mg}$. per cent. (Normal range- $-300 \pm 50 \mathrm{mg}$. per cent.)

Cholesterol/phospholipid $=0.89$ (Normal range $-0 \cdot 8 \pm 0 \cdot 3$ )

Total petroleum ether soluble material $3 \cdot 2 \mathrm{~g}$. per cent. (Normal range very variable; does not usually exceed $1 \mathrm{~g}$. per cent.)

Electrophoretic Lipoprotein Pattern.-Paper electrophoretic patterns prepared by the method of Dangerfield and Smith (1955a) showed a mass of lipid on the origin and in the "trail" extending from the origin to the $\beta$-lipoprotein. A dense pre- $\beta$-lipid component extended to the front of the $\alpha_{2}$-globulin, and the $\beta$-lipoprotein, which was of approximately normal density, was only just discernible in this mass of fat. The $\alpha$-lipoprotein was low. The pattern is compared with a normal lipoprotein pattern in Fig. 3.

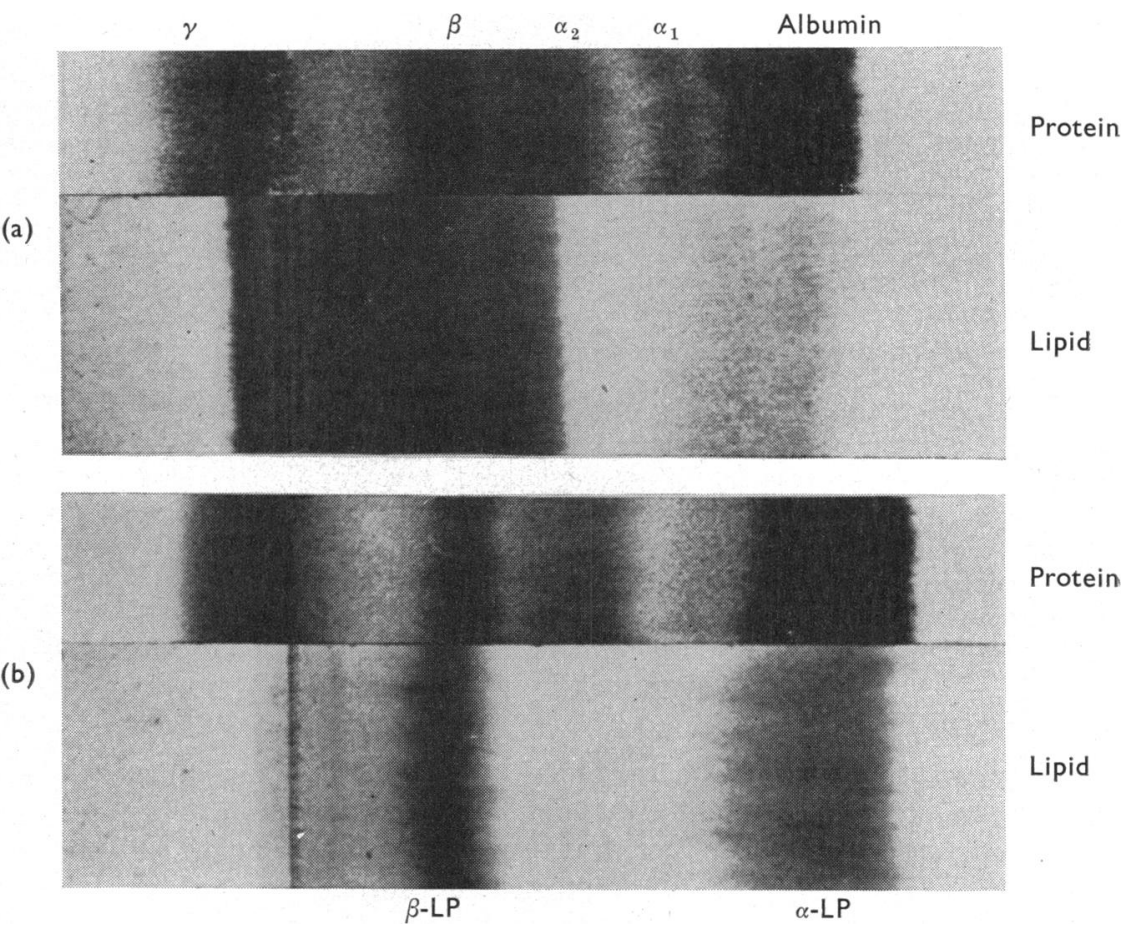

FIG. 3.-Electrophoretic patterns of serum dyed for protein and lipid.

(a) The patient

(b) A normal woman

Response to Intravenous Heparin.-Intravenous injection of $10,000 \mathrm{u}$. heparin temporarily stabilized the lipid emulsion and produced acceleration of the lipids on paper electrophoresis (Dangerfield and Smith, 1955b). Treatment with 10,000 u. 
heparin three times weekly for 3 weeks had no permanent effect on the lipoproteins.

It has been shown that in the majority of subjects acceleration of the $\beta$-lipoprotein occurs after the intravenous injection of as little as $25 \mathrm{u}$. heparin (Smith and Dangerfield, 1955). The acceleration is increased by fat feeding and subjects who do not respond when fasting generally respond after fat feeding. This patient gave no response to $25 \mathrm{u}$. heparin either fasting or after a fatty meal, but responded to $100 \mathrm{u}$. heparin. This presumably indicates some degree of heparin resistance; of two other cases of idiopathic hyperlipaemia tested with $25 \mathrm{u}$. heparin, one responded normally and the other gave no response after feeding.

Glucose Tolerance.-An oral glucose tolerance test yielded normal results. Glycosuria was not present at any time.

\section{Liver Biopsy (Dr. F. D. Bosanquet)}

The liver cells appeared normal; they contained a quantity of glycogen, but this was not considered to be excessive. There was no suggestion of cirrhosis, and the amount of fat present was not obviously increased. In the portion obtained, therefore, there was no evidence of abnormal lipid or glycogen storage and no nests of xanthoma cells, such as described by Thannhauser and Magendantz (1938), were seen. The size of the biopsy specimen, however, was not large.

\section{Other Investigations}

A chest $x$ ray showed moderate left ventricular enlargement, and an electrocardiogram revealed left axis deviation but no other abnormality. The cerebrospinal fluid was normal.

\section{Comment}

Ocular changes in idiopathic hyperlipaemia, with the exception of palpebral xanthomata, arcus lipoides corneae, and lipaemia retinalis, have been recorded only rarely. In the patient reported by Frank and Levitt (1951), xanthomatous deposits were visible on the iris of both eyes. The present case resembles that of Lewis (1950), in which intra-ocular deposits occurred in association with xanthomatous biliary cirrhosis. The patient presented with impaired vision in one eye and examination of the fundus revealed scattered yellowish areas of varying size involving all parts of the fundus. These were situated deep to the retina and at one point had produced retinal detachment. Areas of oedema of the retina with haemorrhages were noted. In the present case, the deposits, apart from the lesion involving the right macula, gave the impression of being more superficially situated.

The blood lipid picture is typical of essential hyperlipaemia, but an unusual finding in this patient is the instability of the lipid emulsion, particularly in view of the very low value of the cholesterol/phospholipid ratio. It is often loosely assumed that phospholipid helps to maintain the other lipids in solution or suspension, but this case suggests that the relationship is very complex because even the ratio of total serum lipid/phospholipid is markedly 
lower than in a comparable case with over 5 per cent. total serum lipid and a perfectly stable lipid emulsion.

Its well-known lipaemia-clearing action provides the rationale for treatment with heparin, and in a few cases it has proved effective (personal communications), but in this case it is possible that both the dosage and the period of treatment were inadequate. The stabilization of the lipid emulsion after heparin injection coupled with some degree of heparin resistance does, however, suggest the possibility that heparin metabolism is in some way connected with the aetiology of the condition.

We wish to thank Dr. B. G. Parsons-Smith for permission to publish details of this case and, with Dr. Michael Kremer, for helpful advice in the preparation of this report. The retinal photograph was prepared by the photographic Department of the Institute of Ophthalmology.

\section{REFERENCES}

Dangerfield, W. G., and Smith, E. B. (1955a). J. clin. Path., 8, 132.

(1955b). Biochem. J., 59, vi (Proceedings of the Biochemical Society).

Frank, L., and LeVITT, L. M. (1951). A.M.A. Arch. Derm. Syph., 64, 434.

LeVer, W. F., SMITH, P. A. J., and HurLeY, N. A. (1954). J. invest. Derm., 22, 33.

LEWIS, N. (1950). Brit. J. Ophthal., 34, 506.

SmITH, E. B. (1956). Ph.D. thesis, Univ. Lond.

and DANGERFIELD, W. G. (1955). III Int. Congr. Biochemistry, Communications 15-20.

ThanNHAUSER, S. J. (1950). "The Lipoidoses". New York.

and MAGENDANTZ, H. (1938). Ann. intern. Med., 11, 1662. 